Photoelectron Spectroscopy of U Oxide at LLNL

J. G. Tobin, S-W. Yu, B. W. Chung, G. D. Waddill

March 3, 2010

MRS Symposium Proceedings

San Francisco, CA, United States

April 6, 2010 through April 9, 2010 
This document was prepared as an account of work sponsored by an agency of the United States government. Neither the United States government nor Lawrence Livermore National Security, LLC, nor any of their employees makes any warranty, expressed or implied, or assumes any legal liability or responsibility for the accuracy, completeness, or usefulness of any information, apparatus, product, or process disclosed, or represents that its use would not infringe privately owned rights. Reference herein to any specific commercial product, process, or service by trade name, trademark, manufacturer, or otherwise does not necessarily constitute or imply its endorsement, recommendation, or favoring by the United States government or Lawrence Livermore National Security, LLC. The views and opinions of authors expressed herein do not necessarily state or reflect those of the United States government or Lawrence Livermore National Security, LLC, and shall not be used for advertising or product endorsement purposes. 
MRS Symposium Proceedings

2010 Spring MRS, San Francisco, CA, April 6 -9, 2010

Actinides Symposium, Symposium Z

\title{
Photoelectron Spectroscopy of U Oxide at LLNL
}

\author{
JG Tobin ${ }^{1, *}, \mathrm{~S}-\mathrm{W} \mathrm{Yu}^{1}$, BW Chung ${ }^{1}$ and GD Waddill ${ }^{2}$ \\ 1. Lawrence Livermore National Laboratory, Livermore, CA, USA \\ 2. Missouri University of Science and Technology, Rolla, MP, USA
}

KEYWORDS: Uranium, oxide, photoelectron spectroscopy

*Corresponding Author: Tobin1@,LLNL.Gov

\begin{abstract}
$\mathrm{X}$-ray photoelectron spectroscopy has been used to characterize a sample of $\mathrm{UO}_{2}$ grown on an underlying substrate of Uranium. Both $\mathrm{AlK} \alpha(1487 \mathrm{eV})$ and $\mathrm{MgK} \alpha(1254 \mathrm{eV})$ emission were utilized as the excitation.

\section{Introduction}

In our laboratory at LLNL, an effort is underway to investigate the underlying complexity of $5 \mathrm{f}$ electronic structure with spin-resolved photoelectron spectroscopy using chiral photonic excitation, i.e. Fano Spectroscopy. Our previous Fano measurements with Ce indicate the efficacy of this approach $[1,2]$ and theoretical calculations and spectral simulations suggest that Fano Spectroscopy may resolve the controversy concerning $\mathrm{Pu}$ electronic structure and electron correlation. $[3,4]$ To this end, we have constructed and commissioned a new Fano Spectrometer, [5] testing it with the relativistic 5d system Pt. $[6,7]$ Here, our preliminary photoelectron spectra of the $\mathrm{UO}_{2}$ system are presented.
\end{abstract}

Much is known about uranium dioxide, as can be found in Wikipedia. [8] "Uranium dioxide or uranium(IV) oxide (UO2), also known as urania or uranous oxide, is an oxide of uranium, and is a black, radioactive, crystalline powder that naturally occurs in the mineral uraninite. $\mathrm{UO} 2$ is used mainly as nuclear fuel, specifically as $\mathrm{UO} 2$ or as a mixture of $\mathrm{UO} 2$ and $\mathrm{PuO} 2$ (plutonium dioxide) called a mixed oxide (MOX fuel) for fuel rods in nuclear reactors. All uranium oxides were used to color glass and ceramics. Uranium oxide-based ceramics become green or black when fired in a reducing atmosphere and yellow to orange when fired with oxygen. Orange-colored Fiestaware is a well-known example of a product with a uranium-based glaze. Uranium oxide has also been used in formulations of enamel, uranium glass, and porcelain. Prior to 1960, uranium oxides were used as colored glazes." [8]

Photoelectron spectroscopy is a photon in-electron out process, with a simple relation governing the energetics: $\mathrm{KE}=\mathrm{hv}-\mathrm{B}_{\mathrm{F}}-\phi$. [9] Here, $\mathrm{KE}$ is the kinetic energy of the ejected electron. $\mathrm{hv}$ is the energy of the incoming photon. $\mathrm{B}_{\mathrm{F}}$ is the binding energy of the electron with respect to the Fermi Level $\left(\mathrm{E}_{\mathrm{F}}\right)$. $\phi$ is a work-function. In our case, $\phi$ is a spectrometerwork-function $\left(\phi_{\mathrm{SP}}\right)$ and $\mathrm{KE}$ is relative to that value. For our spectrometer, $\phi_{\mathrm{SP}}=4 \mathrm{eV}$, so the relations for $\mathrm{AlK} \alpha$ and $\mathrm{MgK} \alpha$ excitation are as follows: $\mathrm{KE}(\mathrm{AlK} \alpha)=1483 \mathrm{eV}-\mathrm{B}_{\mathrm{F}}$ and $\mathrm{KE}(\mathrm{MgK} \alpha)=1250-\mathrm{B}_{\mathrm{F}}$. 
MRS Symposium Proceedings

2010 Spring MRS, San Francisco, CA, April 6 -9, 2010

Actinides Symposium, Symposium Z

\section{Experimental}

The experiments were carried out onsite at Lawrence Livermore National Laboratory, using a spectrometer [5] with capabilities for performing both spin resolved Fano spectroscopy [6,7] and high energy Inverse Photoelectron Spectroscopy (IPES) or Bremstrahlung Isochromat Spectroscopy (BIS). [10] The PES spectra were collected using a Specs x-ray source for the excitation and the Specs photoelectron energy analyzer for electron detection. The polycrystalline, depleted U sample was oxidized by exposure to air at ambient pressures. After introduction to the ultra-high vacuum system, the oxidized sample was bombarded with Ar ions and underwent annealing, to clean the topmost surface region and stabilize the surface and near surface regions. X-ray photoelectron spectroscopy (XPS) data collection occurred with the sample at or near room temperature. In our experiments, the XPS spectra play a critical role: the confirmation of the sample quality. The energy resolution band-pass in the experiment was driven by the broadening contributions of the $\mathrm{x}$-ray tube and electron detection. Using the full-width at half maximum of the core level peaks, it is possible to determine directly the total energy bandpass in the XPS experiments, which is estimated to be about $2 \mathrm{eV}$. As will be discussed below, our sample consisted of a thin layer of $\mathrm{UO}_{2}$ lying above $\mathrm{U}$ metal. Under conditions such as these, thin layers composed of materials that would normally be insulating in the bulk can continue to exhibit a Fermi edge, owing to the thinness of the film and the underlying conductor. [11]

\section{Figure 1}

Sketch for BIS and spin resolved photoelectron spectroscopy (SRPES) experimental setup installed recently at Lawrence Livermore National Lab for the electronic structure study of actinides. For BIS, the detection of the photons is performed with the XES-350 monochromator and multi-channel detector.

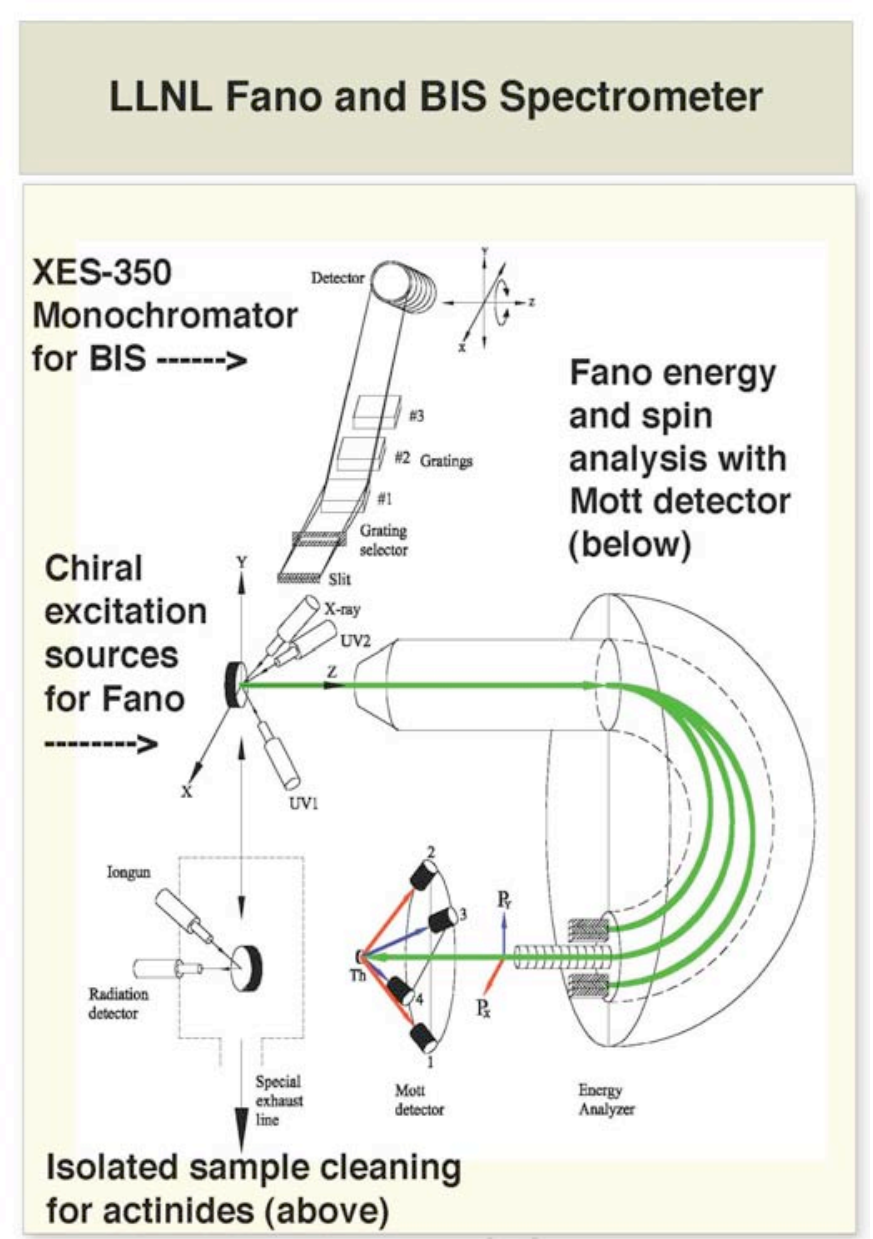




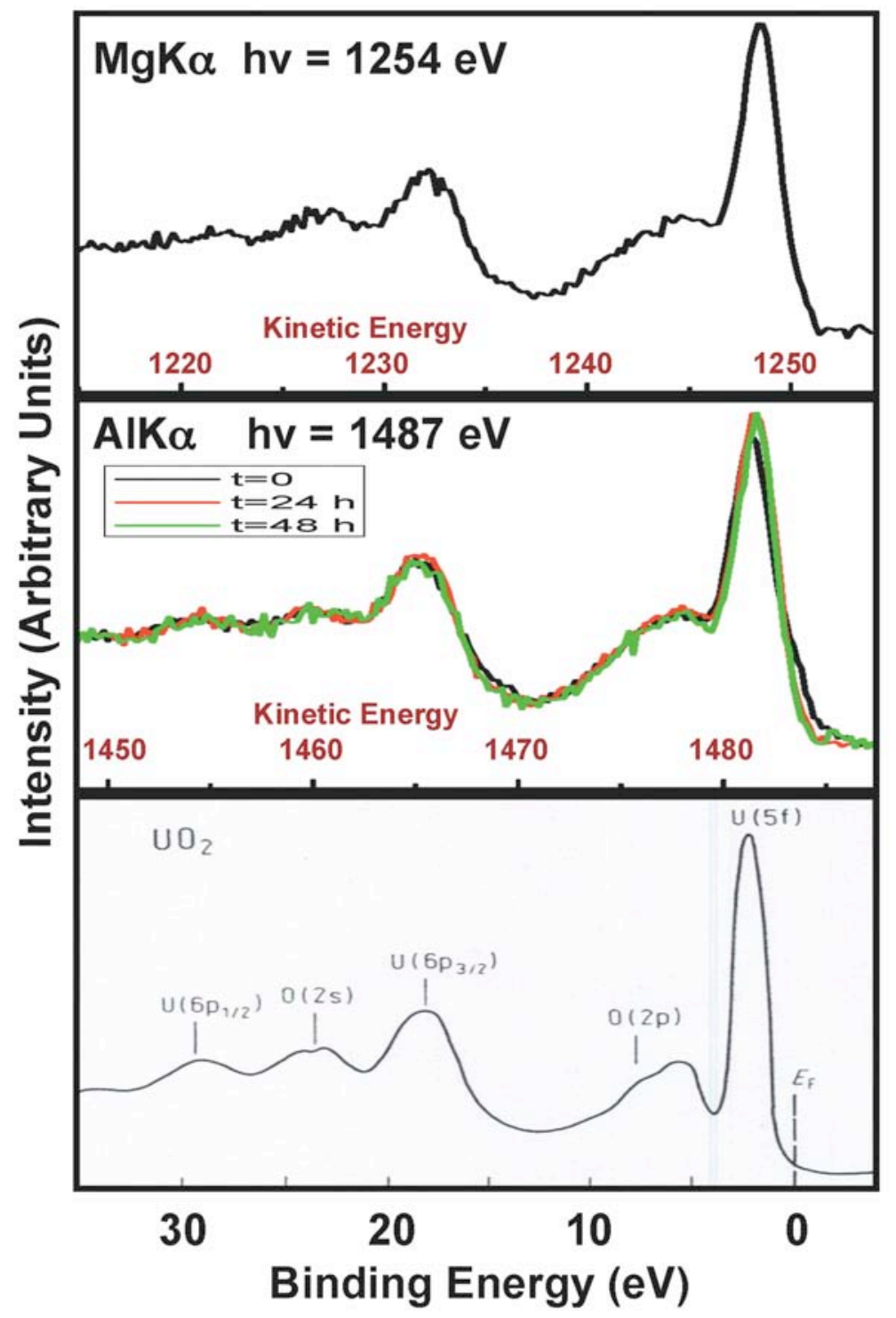

Figure 2

Here is shown the comparison of the valence band spectra with an earlier result by Veal and Lam. [11] Related works can be found in the review study of Naegele. [12] The binding energy scale for all of the spectra is shown at the bottom and the respective $K E$ scales for the AlK $\alpha$ and $M g K \alpha$ spectra are shown in their panels. Top: The $M g K \alpha$ spectrum.

Middle: The AlK $\alpha$ spectrum.

Bottom: The result from Veal and Lam. [11, 12]

\section{Discussion}

To begin, the valence band spectra will be considered. A comparison of the spectra for the LLNL sample versus the earlier work of Veal and Lam is shown in Figure 2. Both the AlK $\alpha$ and $\mathrm{MgK} \alpha$ results are consistent with the earlier work and its assignments. There appears to be no photon-energy-dependence nor variation with time, at least over a 48 hour period. (The time independence will also be seen in the core level spectra below.) This strongly suggests that the sample is $\mathrm{UO}_{2}$, and that it is stable. There appears to be a weak Fermi edge at $0 \mathrm{eV}$ $\left(E_{F}\right)$, consistent with a thin oxide layer grown on top of a metal substrate.

This assignment can be further tested by a examination of the core level and Auger spectra, accessed with the $\mathrm{AlK} \alpha$ and $\mathrm{MgK} \alpha$ radiation. These results will be shown in Figures $3-7$ below. Core level features are photoemission driven and are observed at a constant binding energy, while Auger peaks are generated by an electronic decay mechanism to fill core holes and are thus at fixed kinetic energies. Having both $\mathrm{AlK} \alpha$ and $\mathrm{MgK} \alpha$ excitation permit the separation of the two, as will be shown below. [9] 


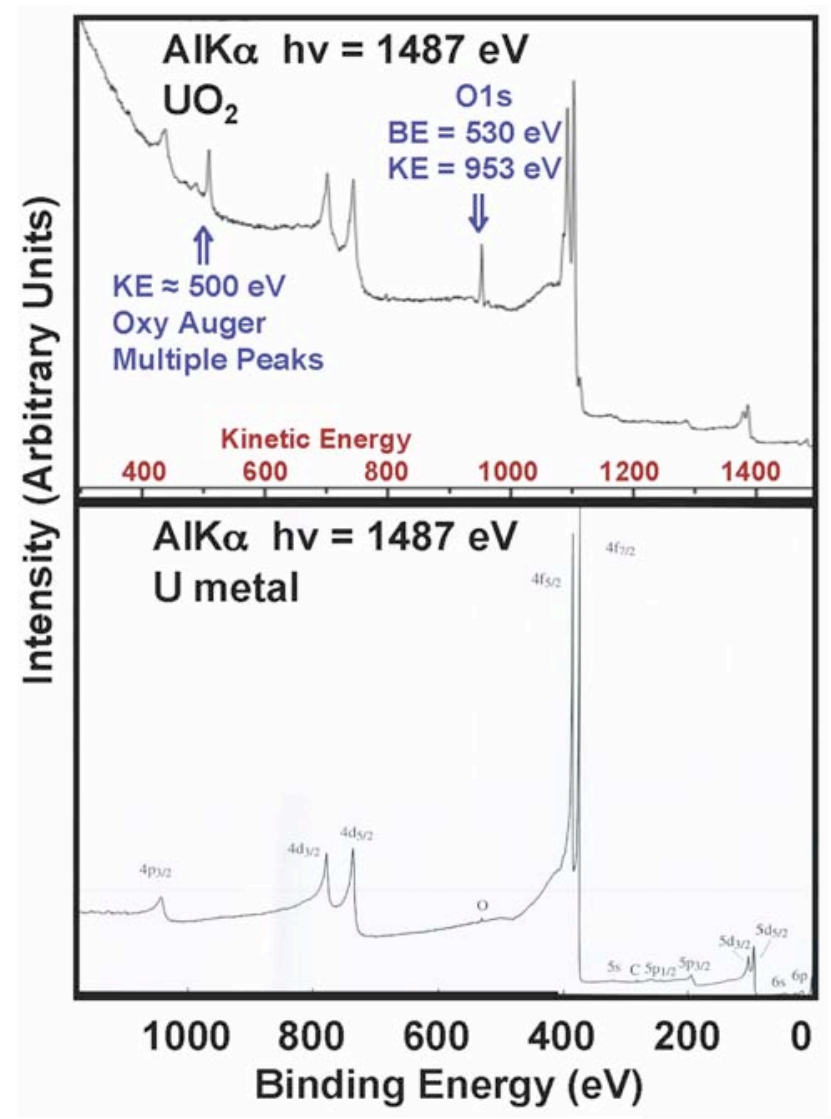

Figure 3

To the left.

A comparison our AlK $\alpha$ wide scan with that of metallic $U$ from

Reference 13. BE is binding energy. As in figure 2, the kinetic energy scale is included.

Figure 4

Below.

A comparison our $\mathrm{MgK \alpha}$ wide scan with that of metallic U from Reference 13, following Figure 3.
Here, the comparison is made between the widescans of the LLNL $\mathrm{UO}_{2}$ sample and the corresponding wide scans for metallic U. [13] For AlK $\alpha$ (Figure 3) and $\operatorname{MgK} \alpha$ (Figure 4), almost all of the spectral features can be seen to be derived from the $U$. The exceptions are the new $\mathrm{O} 1 \mathrm{~s}(\mathrm{BE}=530 \mathrm{eV})$ and Oxygen Auger ( KE near $500 \mathrm{eV})$. There are no other strong features, e.g a carbon line $(\mathrm{C} 1 \mathrm{~s}, \mathrm{BE}=$ $280 \mathrm{eV})$. In the AlK $\alpha$ spectrum, the Oxygen Auger is isolated, but not so in the $\operatorname{MgK} \alpha$ case.

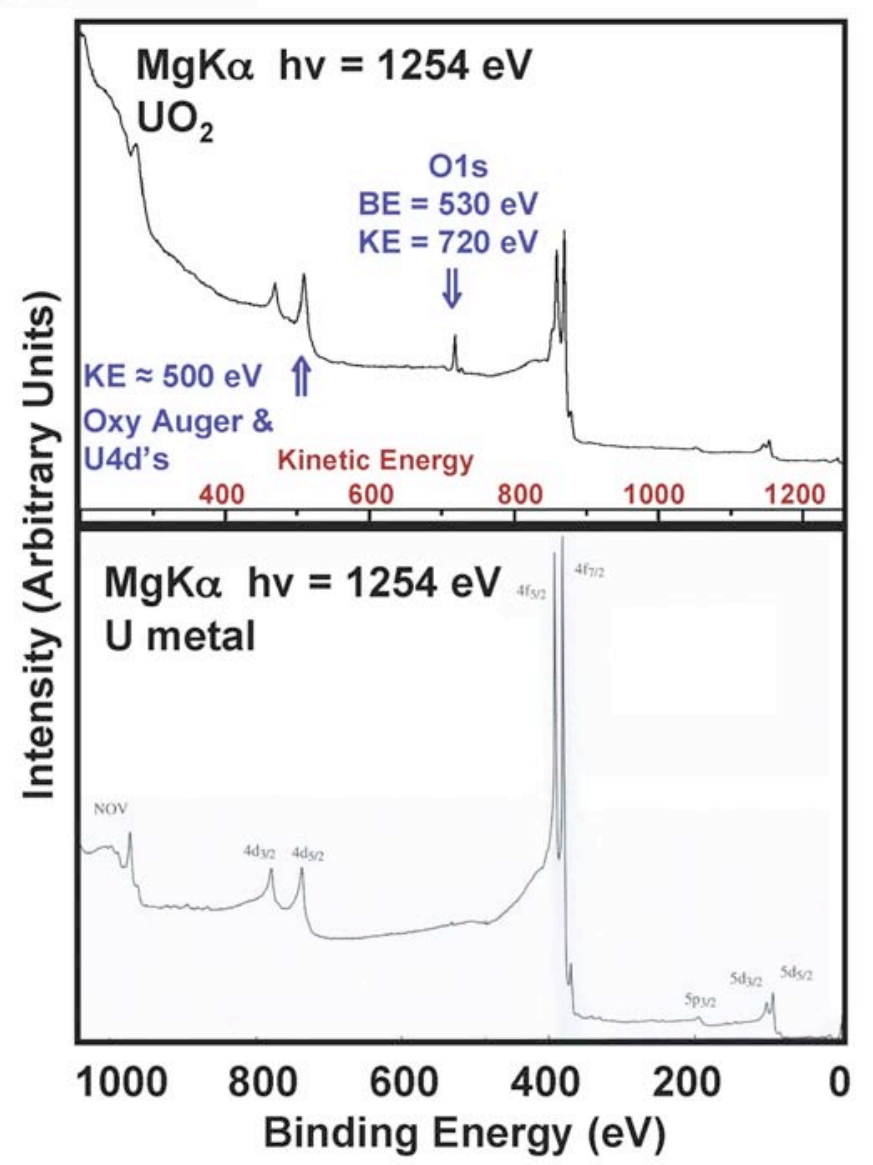


MRS Symposium Proceedings

2010 Spring MRS, San Francisco, CA, April 6 -9, 2010-02-26

Actinides Symposium, Symposium Z

Figure 5 (below)

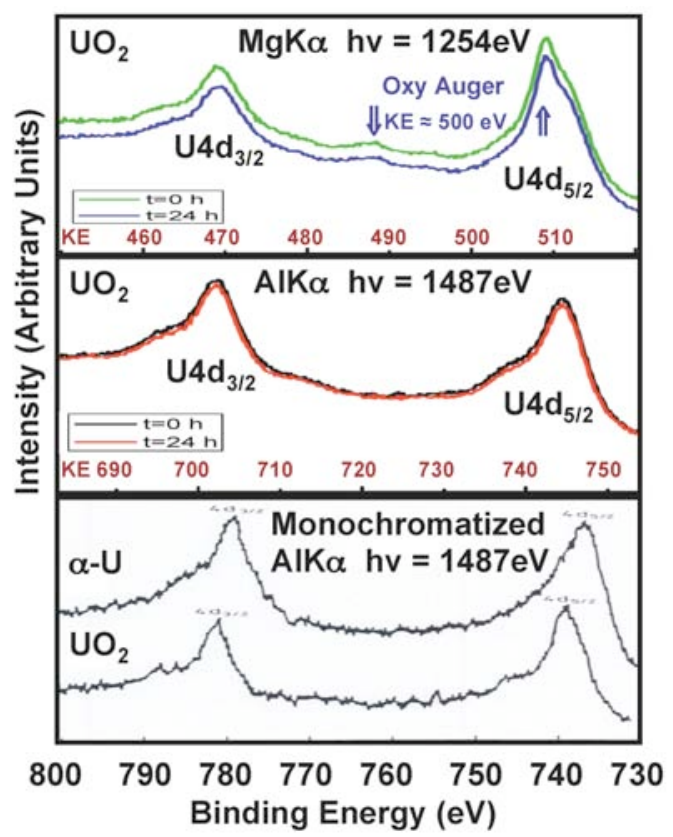

Figure 5 (caption)

The $U 4 d$ spectral region, following

Figures 2-4. The reference spectra are from Ref 12 and 14.

Figure 6 (caption)

The $U$ 4f spectral region, following

Figures 2-4. . The reference spectrum is from Ref 12 and 15.

Figure 7 (caption)

The O1s spectral region, following

Figures 2-4. . The reference spectrum is from Ref 12 and 15.

This overlap can be seen in Figure 5, in the $\mathrm{MgK} \alpha$ spectrum. From the comparison with the reference spectra of Allen at al, the sample is $\mathrm{UO}_{2}$, not $\mathrm{U}$, with the strong shoulder following each of the principal peaks.
Figure 6 (below)

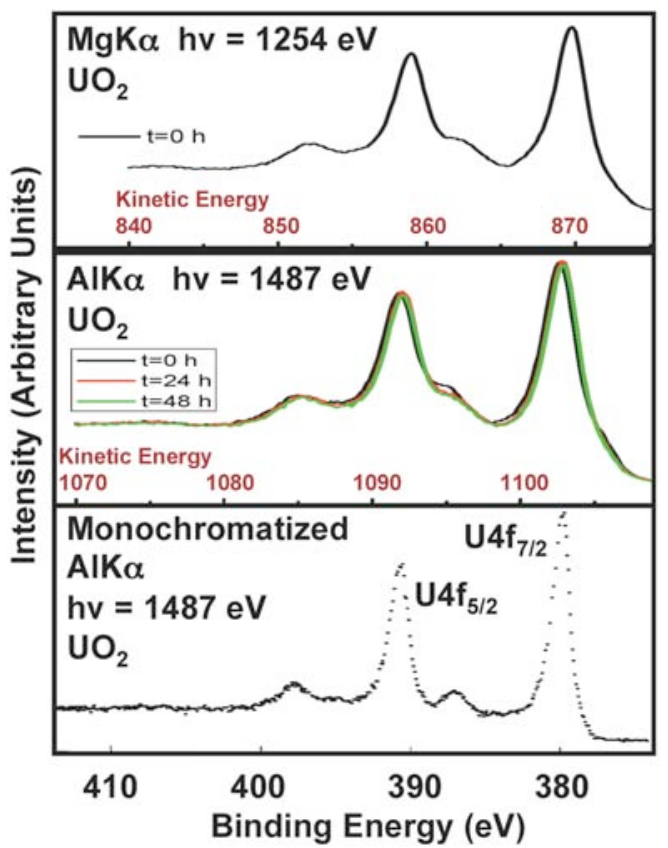

Figure 7 (below)

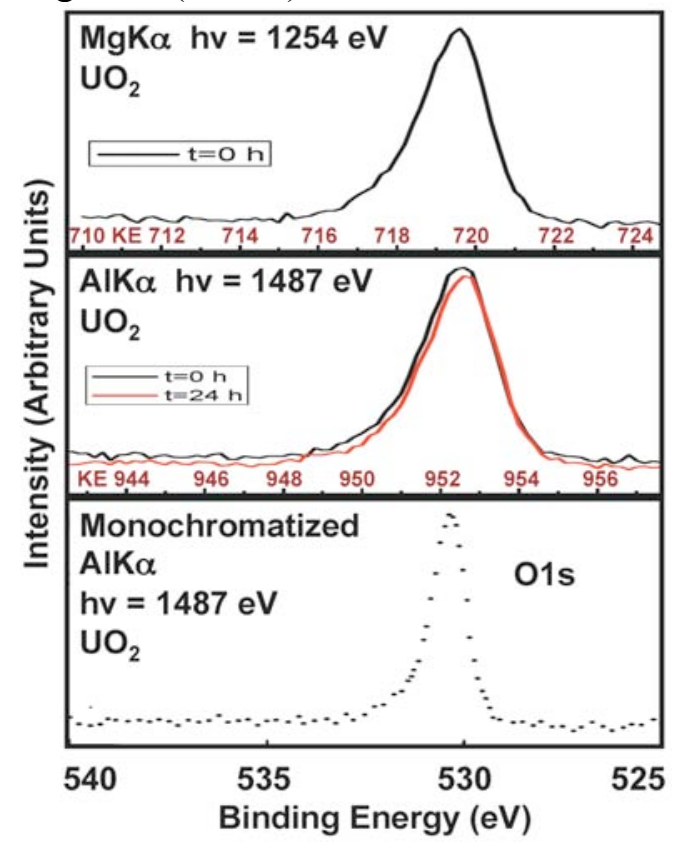

Similar agreement can be found in the case of the $\mathrm{U} 4 \mathrm{f}$ (Figure 6) spectra and O1s spectra (Figure 7). It is of particular importance that the satellite peaks are observed in the $\mathrm{U} 4 \mathrm{f}$ spectra. $\mathrm{UO}_{2}$ has strong satellites, as shown above, but there are none for $\mathrm{U}$ metal. (not shown here) $[12,15,16]$

In these figures, the reference spectra were taken at substantially higher resolution. Thus, while the LLNL spectra recapture the essential features, they are broadened relative to the 
MRS Symposium Proceedings

2010 Spring MRS, San Francisco, CA, April 6 -9, 2010-02-26

Actinides Symposium, Symposium Z

reference spectra. Because the goal of this XPS study was merely to characterize the sample, higher resolution is not required. However, it does afford the chance to properly calibrate our energy band-pass. As can be seen in Figure 7, the full-width-at-half-max is about $2 \mathrm{eV}$, providing a well-grounded estimate of the band-pass.

\section{Summary}

Using XPS and comparing to reference spectra, it has been shown that our sample is clearly $\mathrm{UO}_{2}$.

\section{Acknowledgments}

Lawrence Livermore National Laboratory is operated by Lawrence Livermore National Security, LLC, for the U.S. Department of Energy, National Nuclear Security Administration under Contract DE-AC52-07NA27344. Research supported by the U.S. Department of Energy, Office of Basic Energy Sciences, Division of Materials Sciences and Engineering under Award KC020202/\#SCW0289.

\section{References}

1. J.G. Tobin, S.W. Yu, T. Komesu, B.W. Chung, S.A. Morton, and G.D. Waddill, EuroPhysics Letters 77, 17004 (2007).

2. S.W. Yu, T. Komesu, B.W. Chung, G.D. Waddill, S.A. Morton, and J.G. Tobin, Phys. Rev. B 73, 075116 (2006).

3. S.W. Yu, J.G. Tobin, and P. Söderlind, J. Phys. Cond. Matter 20, 422202 (2008), Fast Track Communication.

4. J.G. Tobin, S.W. Yu, B.W. Chung and G.D. Waddill, J. Nucl. Matl. 385, 31 (2009).

5. J.G. Tobin, S.W. Yu, T. Komesu, B.W. Chung, S.A. Morton, and G.D. Waddill, Matl. Res. Soc. Symp. Proc. 986, 63 (2007).

6. S.W. Yu and J.G. Tobin, Surface Science Letters 601, L127 (2007).

7. S.W. Yu and J. G. Tobin, Phys. Rev. B 77, 193409 (2008).

8. http://en.wikipedia.org/wiki/Uranium dioxide

9. J.G. Tobin, "Photoemission and Inverse Photoemission," in "Determination of Optical Properties," Vol. VIII in Physical Methods of Chemistry, 2nd edition, Ed. B.W. Rossiter and R.C. Bretzold, John Wiley and Sons, New York, 1993, and references therein.

10. J.G. Tobin, S.-W. Yu, B.W. Chung, G.D. Waddill and AL Kutepov, "Narrowing the Range of Possible Solutions to the Pu Electronic Structure Problem: Developing a new Bremstrahlung Isochromat Spectroscopy Capability," IOP Conference Series, Materials Science and Engineering, Actinides 2009 International Meeting, San Francisco, CA, USA, July 12-17, 2009.

11. B.W. Veal and D.J. Lam, Phys. Rev. B 10, 4902 (1974) and Phys. Letters 49A, 466 (1974).

12. J.R. Naegele, "Actinides and Some of their Alloys and Compounds," Electronic Structure of Solids: Photoemission Spectra and Related Data, Landolt-Bornstein "Numerical Data and Functional Relationships in Science and Technology," ed. A Goldmann, Group III, Volume 23b, Pages 183 - 327 (1994).

13. "X-ray Photoelectron Spectra," Physical Electronics Handbook.

14. G.C. Allen, I.R. Trickle and P.M. Tucker, Philos. Mag. B 43, 689 (1981).

15. Y. Baer and J. Schoenes, Solid State Commun. 33, 885 (1980), Y. Baer, Physica 102B, 104 (1980).

16. F. Greuter, E. Hauser, P. Oelhafen, H.-J. Guentherodt, B. Reihl and O. Vogt, Physica 102B, 117 (1980). 